\title{
The correlation of longitudinal/seasonal variations of evening equatorial pre-reversal drift and of plasma bubbles
}

\author{
G. Li ${ }^{1}$, B. Ning ${ }^{1}$, L. Liu ${ }^{1}$, Z. Ren ${ }^{1,2,3}$, J. Lei ${ }^{4}$, and S.-Y. Su ${ }^{5}$ \\ ${ }^{1}$ Institute of Geology and Geophysics, Chinese Academy of Sciences, Beijing, China \\ ${ }^{2}$ Wuhan Institute of Physics and Mathematics, CAS, Wuhan, China \\ ${ }^{3}$ Graduate School of Chinese Academy of Sciences, Beijing, China \\ ${ }^{4}$ High Altitude Observatory, National Center for Atmospheric Research, Boulder, CO, USA \\ ${ }^{5}$ Institute of Space Science, National Central University, Chung-Li, Taiwan
}

Received: 5 September 2007 - Revised: 7 December 2007 - Accepted: 12 December 2007 - Published: 2 January 2008

\begin{abstract}
The evening pre-reversal vertical drift velocity enhancement (PRE) constitutes an important seeding mechanism for the generation of $\mathrm{F}$ region irregularities. Ion density and drift measurements from ROCSAT-1 and DMSP satellites are used to examine the correlation of longitudi$\mathrm{nal} / \mathrm{seasonal}(\mathrm{l} / \mathrm{s})$ variations in the evening pre-reversal vertical drift velocity at the magnetic equator in the topside ionosphere and the plasma bubble (PB) occurrence probability. The analysis performed for three years 2000-2002 (solar maximum), provides consistent evidence as the ground observations that the equatorial PB occurrence is dependent on and increases approximately linearly with PRE, and the 1/s variations of PRE play an important role in the global l/s distribution of PB occurrence. The solstitial evening PRE and equatorial $\mathrm{PB}$ occurrence show similar longitudinal variations: During June solstice, two peaks appear in the African and Pacific longitude sectors, and two minimums are observed in the Indian and American regions; During December solstice, the situation is approximately opposite. The equinoctial longitudinal effects are comparably small. It is concluded that the large-scale $1 / \mathrm{s}$ variations of equatorial PB occurrence can be closely related to the 1/s variations of PRE.
\end{abstract}

Keywords. Ionosphere (Electric fields and currents; Equatorial ionosphere; Ionospheric irregularities)

\section{Introduction}

The low-latitude ionosphere is susceptible to instabilities during the hours after sunset. The absence of sunlight leads to a much faster recombination at lower altitudes than at higher altitudes. This causes a steep upward plasma density gradient existing between the depleted bottomside iono-

Correspondence to: $\mathrm{G} . \mathrm{Li}$

(gzlee@mail.iggcas.ac.cn) sphere and higher density in the upper $\mathrm{F}$ region. The evening equatorial $\mathrm{F}$ region often shows large upward drifts, driven by eastward electric fields. These enhanced vertical drifts, often called the pre-reversal vertical drift velocity enhancements (PRE). Under the action of PRE, the ionosphere is rapidly uplifted and further destabilizes the density perturbations, then the depleted plasma of the lower heights rise up to the topside ionosphere in the form of plasma bubbles (PBs) (Abdu, 2001; Dabas et al., 2003).

The association of the rapid postsunset rise of the equatorial $\mathrm{F}$ layer with the occurrence of spread $\mathrm{F}$ was suggested by the initial observations (Booker and Wells, 1938). Some studies have shown that the height of the nighttime $F$ layer is an important parameter controlling the generation of spread $\mathrm{F}$ (e.g., Abdu et al., 1983; Kelley and Maruyama, 1992). This height is determined by the equatorial vertical drift velocity. Dabas et al. $(1998,2003,2007)$ reported the day-to-day occurrence of scintillations at $4 \mathrm{GHz}$ up to $21^{\circ} \mathrm{N}$ magnetic latitudes is strongly dependent on the evening hour h'F and $\mathrm{dh}$ 'F/dt values over the magnetic equator, and suggested that near magnetic equator, the threshold values of $\boldsymbol{E} \times \boldsymbol{B}$ (or h'F) can be successfully used for the night-to-night prediction of scintillation occurrence. By using radar observations from Jicamarca, Fejer et al. (1999) studied the effects of the F region vertical drift velocity on the generation and evolution of equatorial spread F (ESF), and explained the irregularities occurrence as resulting from the corresponding effects on the evening vertical drifts. Whalen (2003) analyzed the dependence of equatorial spread $\mathrm{F}$ on vertical drift, and reported that ESF occurrence is dependent on and increases approximately linearly with maximum $\boldsymbol{E} \times \boldsymbol{B}$ drift velocity during the Equinox and June solstice. Anderson et al. (2004) examined the relationship between the enhanced upward $\boldsymbol{E} \times \boldsymbol{B}$ drift velocity after sunset and the subsequent scintillation activity for the forecasting on day-to-day basis, and demonstrated that there exists a threshold velocity of $20 \mathrm{~m} / \mathrm{s}$ that determines the scintillation occurrence. As suggested by Basu

Published by Copernicus Publications on behalf of the European Geosciences Union. 
et al. (1996), the evening vertical drift is very important on the generation of irregularities. And they appear to have a direct bearing on the occurrence of equatorial spread $F$.

In the low-latitude regions, the plasma drifts are driven by a complex interaction of $\mathrm{E}$ and $\mathrm{F}$ region electrodynamic processes during geomagnetic quiet time (Richmond, 1995). In the $\mathrm{E}$ region, neutral winds drive zonal and meridional currents. Due to the existence of large divergence in the zonal current at dawn and dusk, large-scale eastward and westward electric fields are produced on the dayside and nightside respectively. These east-west electric fields induce upward and downward plasma motion throughout the equatorial $\mathrm{F}$ region at an $\boldsymbol{E} \times \boldsymbol{B}$ velocity.

The equatorial electric field, plasma drift, and associated phenomena (such as PBs) vary with longitude at a given local time (Sastri, 1996; Su et al., 1996; Doumouya et al., 2003). Walker (1981) provided evidence that the enhancement in the equatorial anomaly after sunset is more pronounced and prolonged at American than at East Asian longitudes. For plasma vertical drift, Ramesh and Sastri (1995) found that the drifts in the Indian zone are always less than at Jicamarca. The ion density measurements from in-situ satellites, such as AE-E, DMSP, KOMPSAT-1 and ROCSAT-1 (e.g., McClure et al., 1998; Park et al., 2005; Gentile et al., 2006; Su et al., 2006), also show longitudinal variations of PBs. These experimental evidences have shown that the equatorial ionosphere behaves differently in various longitude sectors.

Numerical simulations have been used to study the dependence of the evening equatorial electric fields on different physical parameters (e.g., Rishbeth, 1971; Crain et al., 1993; Eccles, 1998a, b). Eccles (1998b) analyzed three proposed causes of the pre-reversal enhancement of the zonal electric field. The simulation results show that the mechanism (Curl of E) proposed by Rishbeth (1971) is fundamental, the other two mechanisms (Divergence of Hall Currents and Equatorial Electrojet (EEJ) current Channel to Nighttime) do not produce the evening enhancement but alter the enhancement shape and magnitude. Fesen et al. (2000) used the NCAR Thermosphere Ionosphere Electrodynamics General Circulation Model (TIEGCM) to show the seasonal and solar cycle variation of the low-latitude plasma drifts. Vichare and Richmond (2005) extended the PRE study of Fesen et al. (2000), and examined the longitudinal pattern of the pre-reversal enhancement in equatorial vertical plasma drift velocities at equinox by using simulations from the Magnetosphere Thermosphere Ionosphere Electrodynamics General Circulation Model (MTIEGCM). They recorded that the vertical drifts in the region from $290^{\circ} \mathrm{E}$ to $20^{\circ} \mathrm{E}$ are stronger than $150-270^{\circ} \mathrm{E}$, which is consistent with observations (Walker, 1981).

Based on in-situ satellite measurements and ground observational results, the analysis of $1 / \mathrm{s}$ variations of $\mathrm{PB}$ occurrence and $\boldsymbol{E} \times \boldsymbol{B}$ drifts has been performed by earlier studies. And the correlation between scintillations and evening vertical drifts $(\boldsymbol{E} \times \boldsymbol{B}$ or h'F) also can be found from cases of ground observation, such as in American and Indian sectors. But global 1/s analysis of the relationship based on observational results is not presented. By using the ROCSAT-1 and DMSP measurements, this paper extends the study of relationship between evening equatorial pre-reversal vertical drift velocity and PB occurrence to the entire longitude and seasons. Its purpose is to investigate the $1 / \mathrm{s}$ dependence and the latitudinal extent of PB occurrence on PRE. Since the effects of geomagnetic activity on $\mathrm{F}$ region irregularities are various and depend on the onset time of magnetic acitiviy (e.g. Aarons 1991; Abdu et al., 1995). In order to remove the storm effects on PRE and PB occurrence, and confine our attention to quiet time variations, only the data of geomagnetic quiet days (defined by an average $K p<3$ ) are used in the following analyses.

\section{Observations}

ROCSAT- 1 is located at $600 \mathrm{~km}$ circular orbit with a $35^{\circ}$ inclined orbital plane observing topside ionospheric ion properties. The ionospheric plasma and electrodynamics instrument (IPEI) on board is designed to take in-situ measurements of ion density and drift velocity etc., over a large dynamic range with high accuracy. The uninterrupted dataset can provide a good statistical result of equatorial drift velocity and $\mathrm{F}$ region irregularity distributions.

The 1-s averaged ROCSAT-1 data of ion density and 10-s averaged drift velocity measurements are used for the current study. The vertical drift data within 5 degree of the magnetic equator are considered as equatorial vertical drifts. For the intention of choosing an appropriate period as evening pre-reversal vertical drift time, we divide the longitude to five sectors. As shown in Fig. 1, from left to right panels, the longitude sectors covered African $\left(0-45^{\circ} \mathrm{E}\right)$, Indian $\left(45-100^{\circ}\right.$ E), Pacific $\left(100-240^{\circ}\right.$ E), American $\left(240-310^{\circ}\right.$ E) and Atlantic $\left(310-360^{\circ} \mathrm{E}\right)$ regions respectively. The vertical drift data are binned in $15 \mathrm{~min}$, and into seasonal bins representing Equinox (spring, March-April), June solstice (MayAugust), Equinox (autumn, September-October) and December solstice (November-February). Figure 1 indicates that the evening pre-reversal upward drift enhancements (PRE) were observed apparently. The vertical dashed line highlight the time of PRE (about 18:00-19:00 LT). By using the vertical drifts from measurements of ionosonde, radar, and AE-E for equinoctial quiet time and high solar maximum conditions, Oyekola (2006) reported the evening peak velocities occur at around 19:00 LT. The PRE near 18:00-19:00 LT is also reported by Kil et al. (2007).

According to Su et al. (2006) reported, the plasma bubble (PB) occurrence can be identified as $\sigma \geq 0.3 \%$. 


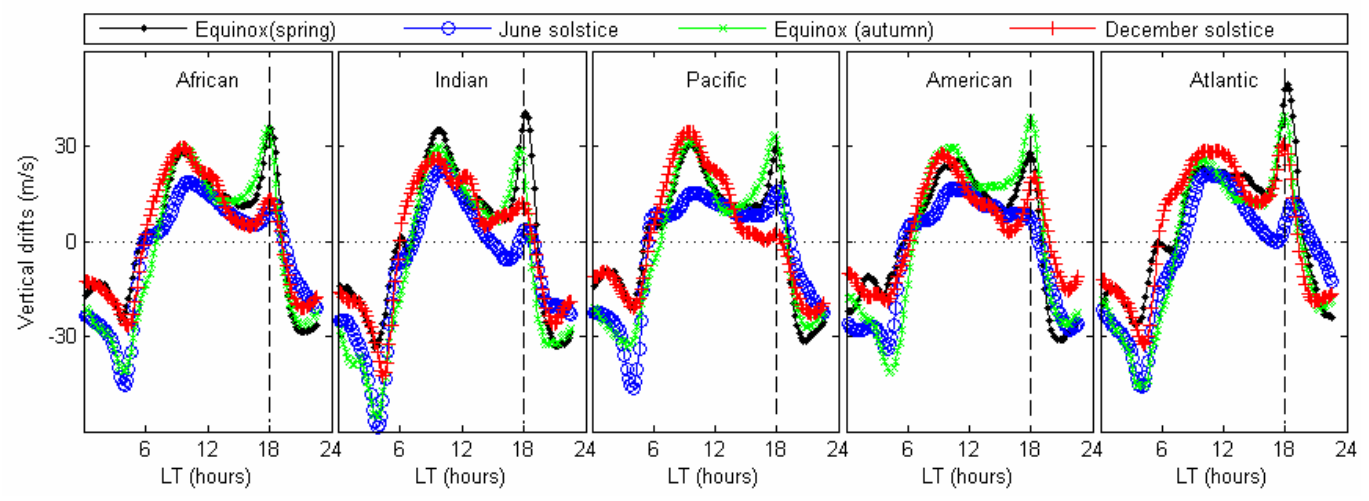

Fig. 1. Seasonal variation of local time (LT) averaged vertical drifts at five longitude sectors representative of the African $\left(\sim 0-45^{\circ}\right)$, Indian $\left(\sim 45-100^{\circ}\right)$, Pacific $\left(\sim 100-240^{\circ}\right)$, American $\left(\sim 240-310^{\circ}\right)$ and Atlantic $\left(\sim 310-360^{\circ}\right)$ regions during the period year $2000-2002$.

The density fluctuation value $\sigma$ is obtained with the following equation:

$\sigma=\frac{\left[\frac{1}{10} \sum_{i=1}^{10}\left(\log n_{i}-\log n_{o i}\right)^{2}\right]^{1 / 2}}{\frac{1}{10} \sum_{i=1}^{10} \log n_{o i}}$

where $n_{i}$ and $n_{o i}$ are the measured ion density and the linearly fitted value at the $i$ th data point respectively. The equation is the standard deviation of ion density variation in logarithmic scale divided by the mean of ion density variation in logarithmic scale for a 10-s segment of data.

In the following, the evening equatorial pre-reversal vertical drift velocity is obtained within the period 18:1019:10 LT. The satellite transit time within a square grid of $20^{\circ}$ in magnetic latitude and $1^{\circ}$ in geographic longitude during the period year 2000-2002 is recorded. And the time duration when the density irregularity structure $\sigma \geq 0.3 \%$ in a square grid is also recorded. The total time duration of the irregularity occurrence is then divided by the satellite transit time to obtain the PB occurrence probability in that longitude grid (for $|\mathrm{MLat}|<=10^{\circ}, 10^{\circ}<\mid$ MLat $\mid<=20^{\circ}$ and $20^{\circ}<\mid$ MLat $\mid<=30^{\circ}$ respectively).

DMSP satellites are in Sun-synchronous polar orbits at altitudes near $840 \mathrm{~km}$ and local times near the equator of 06:00, 09:30, 18:00 and 21:30 LT. Since the vertical drifts derived from the Ion Drift Meter have an absolute uncertainty, relative variations are examined by removing a monthly average from the drift data (Hartman and Heelis, 2007). The 4-s averaged vertical drift measurements within 5 degree of the magnetic equator and near 18:00 LT (DMSP F13) are used as the pre-reversal vertical drifts. The PB occurrence is obtained with DMSP F15 (near 21:30 LT) density for a 20-s segment of data (the same way as ROCSAT-1).

\section{Results and discussion}

Figure 2 shows the longitudinal averaged evening equatorial pre-reversal vertical drift velocity in Spring equinox, June solstice, Autumn equinox and December solstice, and the corresponding plasma bubble $(\mathrm{PB})$ occurrence probability (longitude grid of $\mid$ MLat $\left|<=10^{\circ}, 10^{\circ}<\right|$ MLat $\mid<=20^{\circ}$ and $20^{\circ}<\mid$ MLAT $\mid<=30^{\circ}$ ) versus longitude for ROCSAT- 1 measurements of years 2000-2002. The smooth curve of each panel is fitted to the $15^{\circ}$ longitude mean values. Two features in the longitudinal/seasonal $(1 / \mathrm{s})$ variations are shown here.

Notice first that for all longitude regions, the pre-reversal vertical drift velocity during equinox is larger than solstice, with a lower value (smooth averaged) up to $25 \mathrm{~m} / \mathrm{s}(30 \mathrm{~m} / \mathrm{s}$ ) for Spring (Autumn) equinox, as shown in the top four panels of Fig. 2. On the whole, the second four panels show that the equatorial PBs $\left(|\mathrm{MLat}|<=10^{\circ}\right)$ present a high occurrence probability correspondingly.

The second feature is longitudinal variation of pre-reversal vertical drift and plasma bubble occurrence probability during solstice. Note that the equinoctial drifts and plasma bubble occurrence show only a small longitudinal dependence. Larger longitudinal changes are evident during June and December solstice. The June solstitial pre-reversal vertical drifts have two apparent peaks centered at about $20^{\circ} \mathrm{E}$ (African) and $180^{\circ} \mathrm{E}$ (Pacific) longitude regions respectively, the maximum magnitude of the pre-reversal drifts reach about $25 \mathrm{~m} / \mathrm{s}$ around $180^{\circ} \mathrm{E}$. Ionosonde observations and AE-E satellite vertical drift measurements once show the large pre-reversal enhancement of the June drifts in the longitude sector $160-200^{\circ} \mathrm{E}$ (Abdu et al., 1981; Fejer et al., 1995). For June solstice, the minimum pre-reversal drifts located at Indian $\left(60^{\circ} \mathrm{E}\right)$ and American $\left(290^{\circ} \mathrm{E}\right)$ regions. Furthermore, the December solstitial pre-reversal drifts also present two apparent increments centered near $60^{\circ} \mathrm{E}$ (Indian) and $320^{\circ} \mathrm{E}$ (American-Atlantic) respectively, and the maximum pre-reversal drift velocity nearly reaches $45 \mathrm{~m} / \mathrm{s}$ around 


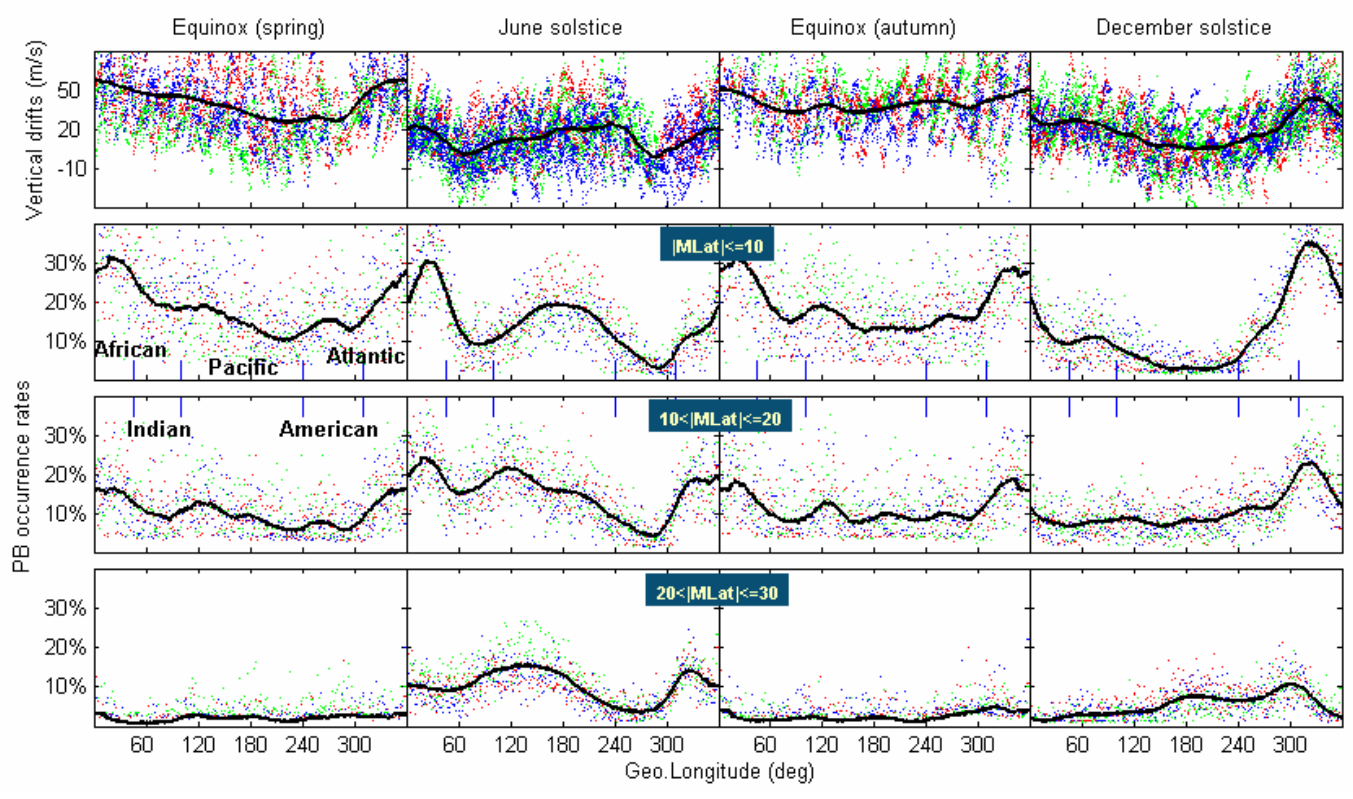

Fig. 2. Seasonal and longitudinal variation of evening equatorial pre-reversal vertical drifts (top panels), and plasma bubble occurrence probability obtained from ROCSAT- 1 during high solar activity periods (the middle and bottom panels represent plasma bubble occurrence probability within $\mid$ MLat $\left|<=10^{\circ}, 10^{\circ}<\right|$ MLat $\mid<=20^{\circ}$ and $20^{\circ}<\mid$ MLat $\mid<=30^{\circ}$; the scatterplot of red, green and blue points represent years 2000, 2001 and 2002 respectively).

$320^{\circ} \mathrm{E}$. The two minimum drifts located at around $20^{\circ} \mathrm{E}$ (African) and $180^{\circ} \mathrm{E}$ (Pacific) longitude sectors. Based on the combined incoherent scatter radar observations at Jicamarca and Ion Drift Meter observations on board the AE-E satellite, Scherliess and Fejer (1999) presented a global empirical model for the quiet time $\mathrm{F}$ region equatorial vertical drifts, and the modeled results indicate that during solar maximum, the June solstice evening peak drifts maximize in the Pacific region with drift amplitudes of up to $35 \mathrm{~m} / \mathrm{s}$, whereas the December solstice velocities maximize in the American sector with comparable magnitudes. The equinoctial peak velocities vary between about 35 and $45 \mathrm{~m} / \mathrm{s}$. Although there exist some discrepancies between the observed amplitudes of peak velocities and the modeled results (probably induced by the difference of selected reversal time and of orbital height), the global 1/s variations of pre-reversal vertical drift velocities obtained from ROCSAT- 1 are similar as the modeled results.

On the other hand, the global 1/s distribution of PB occurrence has been reported (e.g. Kil and Heelis, 1998; McClure et al., 1998; Burke et al., 2004; Park et al., 2005; $\mathrm{Su}$ et al., 2006). Here our main objective of considering PB is to investigate the relation between PB occurrence and pre-reversal vertical drift. As shown in the middle and bottom panels of Fig. 2, two peaks are noticed in longitude sectors Atlantic- African (centered at $20^{\circ} \mathrm{E}$ ) and Pacific (centered at $180^{\circ} \mathrm{E}$ ) regions during June solstice for all three latitudinal belts $\left(\mid\right.$ MLat $\left|<=10^{\circ}, 10^{\circ}<\right|$ MLat $\mid<=20^{\circ}$ and $20^{\circ}<\mid$ MLat $\mid<=30^{\circ}$ ), it indicates that these two longitude regions are very prone to the occurrence of plasma bubbles (PBs) during June solstitial months. For December solstice, regions of high occurrence rates shift to longitudes $70^{\circ} \mathrm{E}$ (Indian) and $320^{\circ} \mathrm{E}$ (American-Atlantic), and it is noted that the $\mathrm{PB}$ occurrence is always maximum near $320^{\circ} \mathrm{E}$ for all three latitudinal belts. There are many factors that may contribute to the $1 / \mathrm{s}$ variation of equatorial PBs. McClure et al. (1998) suggested that the global variation of seeding mechanism that triggers the instability is the key factor in providing a satisfactory explanation to the observed global $1 / \mathrm{s}$ distribution of irregularities. Combining the solstitial longitudinal variation of evening equatorial pre-reversal vertical drift velocity, the longitudinal variation of the PB occurrence should be due at least in part to the strong dependence of the evening equatorial pre-reversal vertical drifts on longitude.

Figure 3 shows the PB occurrence of three latitudinal belts associated with the evening equatorial topside pre-reversal vertical drift velocity for the same longitude grid. A clear relation exists between the magnitude of the pre-reversal enhancement and equatorial PB occurrence: stronger prereversal enhancement presents, the irregularities are more likely to develop. In the equinoctial months, bubble occurrence increases with increasing drift velocity. The drift velocity is greater than $20 \mathrm{~m} / \mathrm{s}$, and the equatorial PB occurrence is larger than $10 \%$. In the solstice, the dependence of equatorial PB occurrence on vertical drift shows similar character, but the drift velocity is much lower than in the 


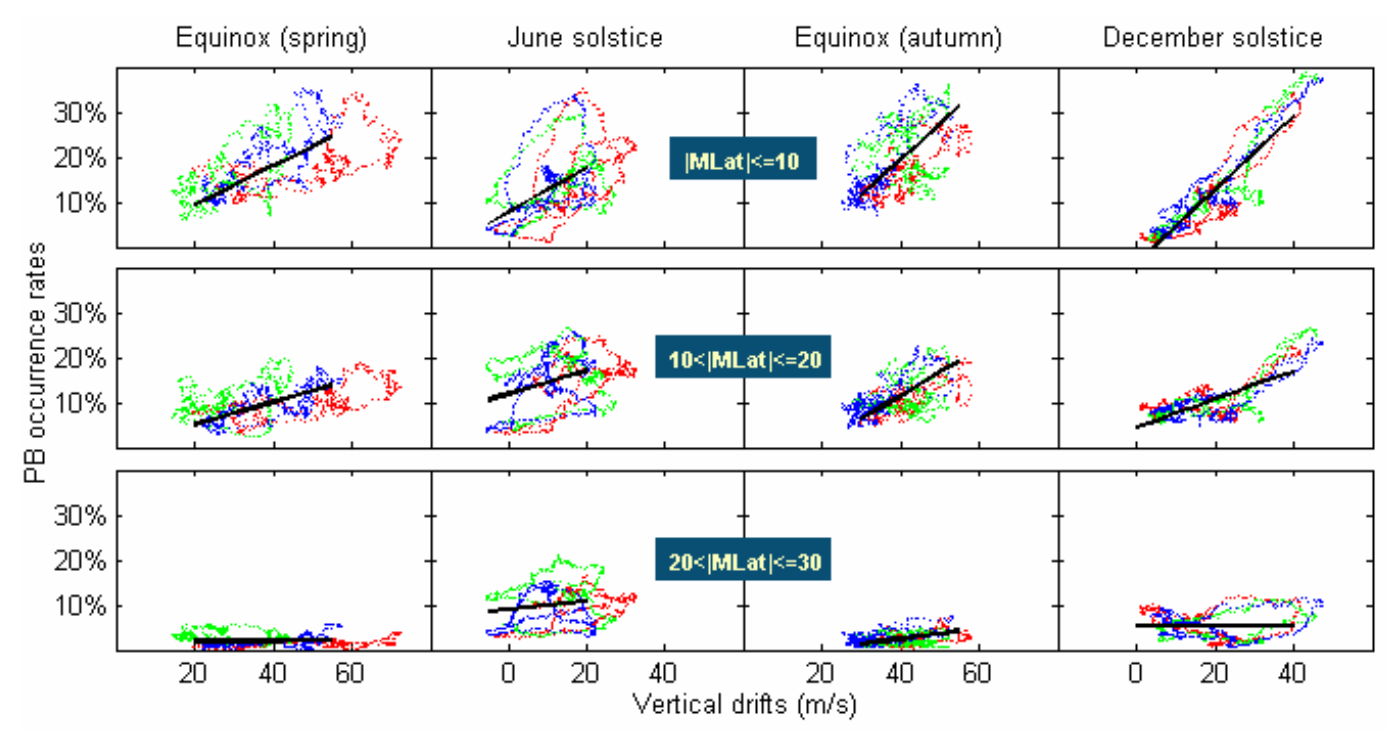

Fig. 3. Plot of the plasma bubble occurrence probability and the evening equatorial pre-reversal vertical drifts for the same longitude grid during the period year 2000-2002.

equinoctial months. For latitudinal belt $10^{\circ}<\mid$ MLat $\mid<=20^{\circ}$, it is noted that during equinoctial months and December solstice, the PB occurrence probability also shows linearly increase with pre-reversal vertical drift. It probably indicates that the PB occurrence at higher latitude is conditional to the occurrence at lower latitudes, and shows association with the generation of equatorial PBs. However during June solstice, the relation between them is weak. Similar features of spread-F occurrence were reported by Dabas et al. (2007) at equatorial anomaly station Delhi, and they suggested that during summer months the spread-F activity seems to be of local origin. The bottom panels of Fig. 3 show weak correlation of PB occurrence and of equatorial pre-reversal drift, and the occurrence rate is always lower than other two latitudinal belts.

In Fig. 4 we present the longitudinal variation of the relative vertical drifts in the topside ionosphere near $840 \mathrm{~km}$ and 18:00 LT, and the DMSP PB occurrence near 21:30 LT. These data are obtained from the DMSP-F13 and -F15 satellites during years 2000-2002. The smooth curve of each panel is fitted to the $15^{\circ}$ longitude mean values. As shown in the top panels, we may note that during June solstice, two minimum (downward) relative vertical drifts about $-30 \mathrm{~m} / \mathrm{s}$ and $-10 \mathrm{~m} / \mathrm{s}$ appear in regions around $320^{\circ} \mathrm{E}$ (AmericanAtlantic) and $80^{\circ} \mathrm{E}$ (Indian); however during December solstice, there exist maximum (upward) relative vertical drifts, about $10 \mathrm{~m} / \mathrm{s}$. The large longitudinal variations of relative vertical drifts during solstice show similar character as ROCSAT-1 measurements. The longitude regions located by upward (downward) relative velocity are consistent with peak (trough) velocity presented in the top panels of Fig. 2 .

The middle and bottom panels of Fig. 4 show the
DMSP PB occurrence of different latitudinal belts. First we note that during equinox, there exists a maximum $\mathrm{PB}$ occurrence around Atlantic-Africa (centered $0^{\circ} \mathrm{E}$ ) regions $\left(\mid\right.$ MLat $\left.\mid<=10^{\circ}\right)$. During solstitial seasons, two peaks are observed at $20^{\circ} \mathrm{E}$ and $180^{\circ} \mathrm{E}$ for June solstice, and $70^{\circ} \mathrm{E}$ and $320^{\circ} \mathrm{E}$ for December solstice. These characteristics are nearly same as those of ROCSAT-1 PB occurrence presented in the second panels of Fig. 2. Based on the similarities of 1/s dependence, it is possible to infer equatorial $\mathrm{PB}$ occurrence probability by means of evening maximum $\boldsymbol{E} \times \boldsymbol{B}$ drift.

During geomagnetic quiet periods, the equatorial vertical plasma drifts result from the combined effects of $E$ and $F$ region electrodynamic processes. Owing to the day-to-night decrease of the $\mathrm{E}$ layer conductivity that establishes itself as a strong longitudinal gradient across the sunset terminator, a significantly reduced loading of the $\mathrm{F}$ region electric field by $\mathrm{E}$ region conductivity occurs toward the nightside. Under such a situation the action of an eastward thermospheric wind in the $\mathrm{F}$ region can produce by dynamo action, vertical (downward) electric field increasing toward the nightside, which leads to the enhanced zonal electric field (Abdu et al., 2003). And so the enhanced pre-reversal vertical drifts.

The PRE development and its longitudinal variation are still not fully understood due to various parameters which make the physical interpretation complex. On principles of electrical coupling between the $\mathrm{E}$ and $\mathrm{F}$ layer, the PRE was originally modeled by Heelis et al. (1974). The basis relationship between the $\mathrm{F}$ region dynamo vertical electric field and the zonal electric field that constitute the PRE arise from a curl-free requirement for electric field as proposed by Rishbeth (1971), which seems to be the fundamental mechanism for the PRE (Eccles, 1998a, b). However, the 


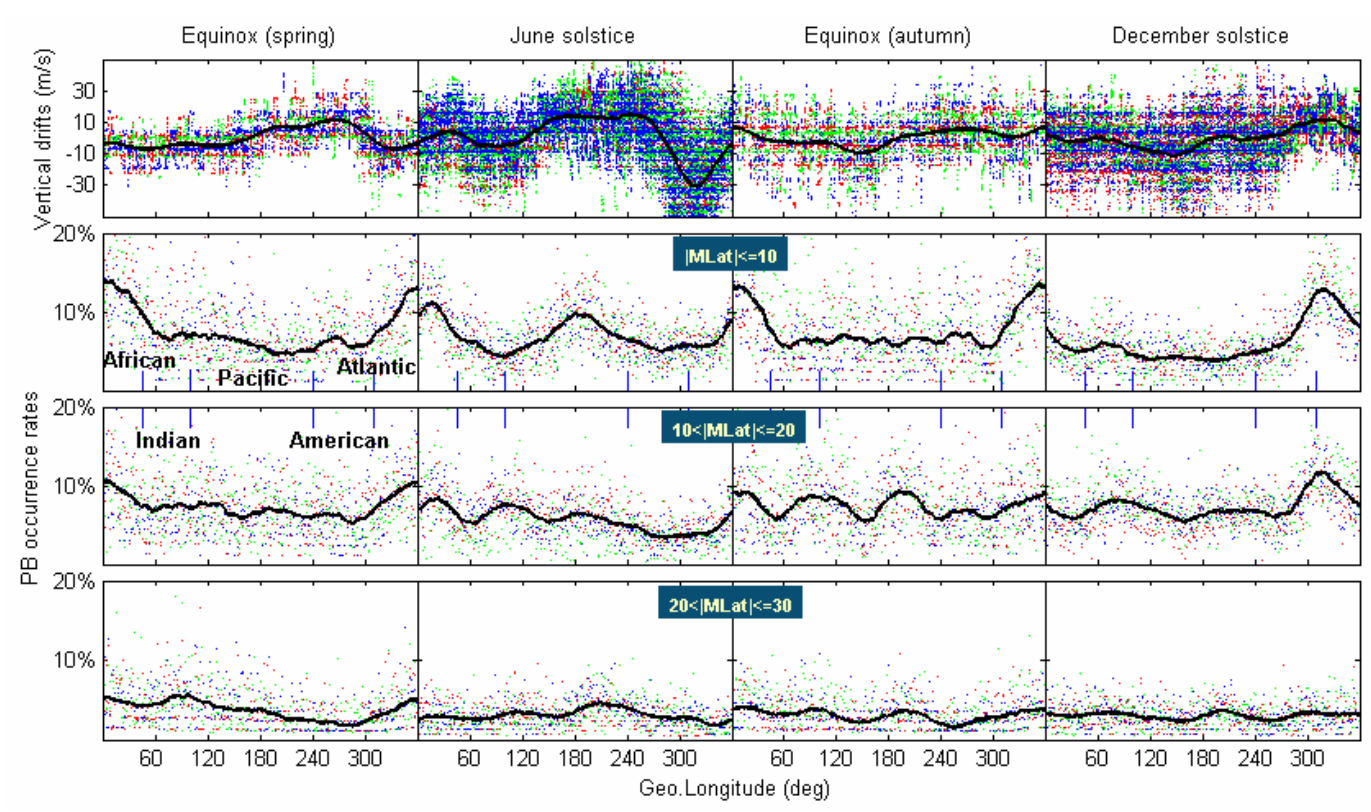

Fig. 4. Plot of the relative variations of evening equatorial vertical drift (obtained from DMSP F13, near 18:00 LT) (top panels), and plasma bubble occurrence probability (obtained from DMSP F15, near 21:30 LT) (middle and bottom panels) versus longitude for equinoctial and solstitial seasons.

PRE seems to involve other distinct contributions as well. Farley et al. (1986) have shown that a zonal electric field enhancement could arise from charge collection in the offequatorial $\mathrm{E}$ region resulting from the divergence of Hall current, which is driven by the $\mathrm{F}$ region downward polarization field mapped down to the conjugate E regions. Haerendel and Eccles (1992) proposed the Cowling conductivity gradient in the EEJ at sunset, which requires enhanced zonal electric fields involving vertical currents and an F region dynamo current system on the nightside, as contribution to the development of the PRE.

According to the presented results (Batista et al., 1986; Crain et al., 1993; Abdu et al., 1995), it is evident that the magnitude and local time structure of the zonal wind as well as that of the longitudinal conductivity gradient across the terminator could control the PRE. By using simulations from MTIEGCM, Vichare and Richmond (2005) examined the relations among the longitude variations of the pre-reversal vertical drift, the conductivity, the eastward wind velocity, the geomagnetic declination, and gradients of the wind and declination during equinox. Few clear correlations are found except in the longitude range between $290^{\circ} \mathrm{E}$ and $20^{\circ} \mathrm{E}$, in that zone higher values of the vertical drifts are associated with the large gradient of declination.

\section{Conclusions}

This paper investigates the correlation of global longitudinal/seasonal variation of evening equatorial pre-reversal ver- tical drift and of plasma bubble occurrence. The main conclusions of this study are the following: (1) There exist apparent longitudinal variations in the solstitial evening equatorial topside pre-reversal vertical drift enhancement (PRE). The dominant longitudinal variation is characterized by two PRE maximums that appear in the African (centered near $\left.20^{\circ} \mathrm{E}\right)$ and Pacific $\left(180^{\circ} \mathrm{E}\right)$ longitude regions, and two minimums locate in the Indian $\left(60^{\circ} \mathrm{E}\right)$ and American $\left(290^{\circ} \mathrm{E}\right)$ sectors during June solstice. For December solstice, two PRE maximums are observed in the Indian $\left(60^{\circ} \mathrm{E}\right)$ and AmericanAtlantic $\left(320^{\circ} \mathrm{E}\right)$ regions respectively. The global 1/s variations of pre-reversal vertical drifts obtained from ROCSAT-1 show similar character as the modeled results (Scherliess and Fejer, 1999). (2) Close to longitude sectors maximum PRE presented, there exist high occurrence probability of plasma bubbles (PBs), and the PB occurrence also exhibits similar longitudinal variations during solstice. The equinoctial longitudinal effects for PRE and PB occurrence are small. This signature of similar global large-scale 1/s distribution of evening equatorial pre-reversal vertical drift velocity and equatorial PB occurrence indicated that the global $1 / \mathrm{s}$ variation of PRE has an important contribution to the observed global 1/s distribution of PB occurrence. (3) Relative vertical drift measurements from DMSP satellite reveal that two maximum relative vertical drifts (upward) appeared in regions around $20^{\circ} \mathrm{E}$ and $180^{\circ} \mathrm{E}$, and two minimums (downward) located near $80^{\circ} \mathrm{E}$ and $320^{\circ} \mathrm{E}$ during June solstice. The longitude regions located by upward (downward) relative drift velocity are consistent with peak (trough) velocity obtained from ROCSAT-1 drift measurements. The 
agreement between the results from ROCSAT- 1 and DMSP datasets picked from three years 2000-2002, indicate that the equatorial PB occurrence probably can be directly related to maximum pre-reversal $\boldsymbol{E} \times \boldsymbol{B}$ drift in some conditions.

Acknowledgements. This research was supported by National Natural Science Foundation of China (40574072, 40374054) and the KIP Pilot Project (KZCX3-SW-144) of Chinese Academy of Sciences and partly supported by Chinese Arctic and Antarctic Administration (20070209). The authors acknowledge UT-Dallas for providing the DMSP datasets, and also SPIDR for providing the Kp index in the web site.

Topical Editor M. Pinnock thanks two anonymous referees for their help in evaluating this paper.

\section{References}

Aarons, J.: The role of the ring current in the generation and inhibition of equatorial $\mathrm{F}$ layer irregularities during magnetic storms, Radio Sci., 26, 1131-1149, 1991.

Abdu, M. A., Bittencourt, J. A., and Batista, I. S.: Magnetic declination control of the equatorial $\mathrm{F}$ region dynamo electric field development and spread F, J. Geophys. Res., 86, 11 443-11 445, 1981.

Abdu, M. A., Medeiros, R. T., Bittencourt, J. A., and Batista, I. S.: Vertical ionization drift velocities and range type spread $\mathrm{F}$ in the evening equatorial ionosphere, J. Geophys. Res., 88, 399-402, 1983.

Abdu, M. A., Batista, I. S., Walker, G. O., Sobral, J. H. A., Trivedi, N. B., and de Paula, E. R.: Equatorial ionospheric electric fields during magnetospheric disturbances: Local time/longitudinal dependencies from recent EITS campaigns, J. Atmos. Terr. Phys., 57, 1065-1083, 1995.

Abdu, M. A.: Outstanding problems in the equatorial ionospherethermosphere electrodynamics relevant to spread F, J. Atmos. Sol.-Terr. Phy., 63, 869-884, 2001.

Abdu, M. A., MacDougall, J. W., Batista, I. S., Sobral, J. H. A., and Jayachandran, P. T.: Equatorial evening prereversal electric field enhancement and sporadic E layer disruption: A manifestation of $\mathrm{E}$ and $\mathrm{F}$ region coupling, J. Geophys. Res., 108(A6), 1254, doi:10.1029/2002JA009285, 2003.

Anderson, D. N., Reinisch, B., Valladares, C. E., Chau, J., and Veliz, O.: Forecasting the occurrence of ionospheric scintillation activity in the equatorial ionosphere on day-to-day basis, J. Atmos. Sol.-Terr. Phy., 66, 1567-1572, 2004.

Basu, S., Kudeki, E., Bsau, Su., et al.: Scintillations, plasma drifts, and neutral winds in the equatorial ionosphere after sunset, J. Geophys. Res., 101, 26 795-26 809, 1996.

Batista, I. S., Abdu, M. A., and Bittencourt, J. A.: Equatorial F region vertical plasma drift: Seasonal and longitudinal asymmetries in the American sector, J. Geophys. Res., 91, 12 055$12065,1986$.

Booker, H. and Wells, H. W.: Scattering of radio waves in the F region of the ionosphere, J. Geophys. Res., 43, 249-256, 1938.

Burke, W. J., Gentile, L. C., Huang, C. Y., Valladares, C. E., and Su, S.-Y.: Longitudinal variability of equatorial plasma bubbles observed by DMSP and ROCSAT, J. Geophys. Res., 109, A12301, doi:10.1029/2004JA010583, 2004.
Crain, D. J., Heelis, R. A., Bailey, G. J., and Richmond, A. D.: Lowlatitude plasma drifts from a simulation of the global atmospheric dynamo, J. Geophys. Res., 98, 6039-6046, 1993.

Dabas, R. S., Lakshmi, D. R., and Reddy, B. M.: Day-to-day variability in the occurrence of equatorial and low latitude scintillations in the Indian zone, Radio Sci., 33, 89-96, 1998.

Dabas, R. S., Singh, L., Lakshmi, D. R., Subramanyam, P., Chopra, P., and Garg, S. C.: Evolution and dynamics of equatorial plasma bubbles: Relationships to ExB drift, postsunset total electron content enhancements, and equatorial electrojet strength, Radio Sci., 38(4), 1075, doi:10.1029/2001RS002586, 2003.

Dabas, R. S., Das, R. M., Sharma, K., Garg, S. C., Devasia, C. V., Subbarao, K. S. V., Niranjan, K., and Rama Rao, P. V. S.: Equatorial and low latitude spread-F irregularity characteristics over the Indian region and their prediction possibilities, J. Atmos. Sol.-Terr. Phy., 69, 685-696, 2007.

Doumouya, V., Cohen, Y., Arora, B. R., and Yumoto, K.: Local time and longitude dependence of the equatorial electrojet magnetic effects, J. Atmos. Sol.-Terr. Phy., 65, 1265-1274, 2003.

Eccles, J. V.: A simple model of low-latitude electric fields, J. Geophys. Res., 103, 26 699-26 708, 1998a.

Eccles, J. V.: Modelling investigation of the evening pre-reversal enhancement of the zonal electric field in the equatorial ionosphere, J. Geophys. Res., 103, 26 709-26 720, 1998 b.

Farley, D. T., Bonelli, E., Fejer, B. G., and Larsen, M. F.: The prereversal enhancement of the zonal electric field in the equatorial inosphere, J. Geophys. Res., 91, 13 723-13 728, 1986.

Fejer, B. G., de Paula, E. R., Heelis, R. A., and Hanson, W. B.: Global equatorial ionospheric vertical plasma drifts measured by the AE-E satellite, J. Geophys. Res., 100, 5769-5776, 1995.

Fejer, B. G., Scherliess, L., and de Paula, E. R.: Effects of the vertical plasma drift velocity on the generation and evolution of equatorial spread F, J. Geophys. Res., 104, 19859-19869, 1999.

Fesen, C. G., Crowley, Robe, R. G., Richmond, A. D., and Fejer, B. G.: Simulation of the pre-reversal enhancement in the low latitude vertical ion drifts, Geophys. Res. Lett., 27, 1851-1854, 2000.

Gentile, L.C., Burke, W. J., and Rich, F. J.: A climatology of equatorial plasma bubbles from DMSP 1989-2004, Radio Sci., 41, RS5S21, doi:10.1029/2005RS003340, 2006.

Haerendel, G. and Eccles, J. V.: The Role of the Equatorial Electrojet in the Evening Ionosphere, J. Geophys. Res., 97(A2), 11811192, doi:10.1029/91JA02227, 1992.

Hartmanm, W. A. and Heelis, R. A.: Longitudinal variations in the equatorial vertical drift in the topside ionosphere, J. Geophys. Res., 112, A03305, doi:10.1029/2006JA011773, 2007.

Heelis, R. A., Kendall, D. C., Moffett, R. J., Windle, D. W., and Rishbeth, H.: Electric coupling of the $\mathrm{E}$ and $\mathrm{F}$ regions and its effects on F region fields and winds, Planet. Space. Sci., 22, 743750, 1974.

Kelley, M. C. and Maruyama, T.: A diagnostic method for equatorial spread F, 2, The effect of magnetic activity, J. Geophys. Res., 97, 1271-1277, 1992.

Kil, H. and Heelis, R. A.: Global distribution of density irregularities in the equatorial ionosphere, J. Geophys. Res., 103, 407-420, 1998.

Kil H., Oh, S.-J., Kelley, M. C., Paxton, L. J., England, S. L., Talaat, E., Min, K.-W., and Su, S.-Y.: Longitudinal structure of the vertical $\mathbf{E} \times \mathbf{B}$ drift and ion density seen from ROCSAT-1, Geophys. 
Res. Lett., 34, L14110, doi:10.1029/2007GL030018, 2007.

McClure, J. P., Singh, S., Bamgboye, D. K., Johnson, F. S., and Kil, H.: Occurrence of equatorial $F$ region irregularities: Evidence for tropospheric seeding, J. Geophys. Res., 103, 29 119-29 129, 1998.

Oyekola, O. S.: Comparison between nighttime ionosonde, incoherent scatter radar, AE-E satellite, and HF Doppler observations of $F$ region vertical electrodynamic plasma drifts in the vicinity of the magnetic equator, J. Geophys. Res., 111, A11318, doi:10.1029/2006JA011844, 2006.

Park, J., Min, K. W., Kim, V. P., Kil, H., Lee, J.-J., Kim, H.J., Lee, E., and Lee, D. Y.: Global distribution of equatorial plasma bubbles in the premidnight sector during solar maximum as observed by KOMPSAT-1 and Defense Meteorological Satellite Program F15, J. Geophys. Res., 110, A07308, doi:10.1029/2004JA010817, 2005.

Ramesh, K. B. and Sastri, J. H.: Solar cycle and seasonal variation in F region vertical drifts over Kodaikanal, India, Ann. Geophys., 19, 633-640, 1995, http://www.ann-geophys.net/19/633/1995/.

Richmond, A. D.: Modeling equatorial ionospheric electric fields, J. Atmos. Terr. Phys., 57, 1103-1115, 1995.

Rishbeth, H.: Polarization fields produced by winds in the equatorial F-region, Planet. Space. Sci., 19, 357-369, 1971.
Sastri, J. H.: Longitudinal dependence of equatorial F region vertical plasma drifts in the dusk sector, J. Geophys., Res., 101, 24452452, 1996.

Scherliess, L. and Fejer, B. G.: Radar and satellite global equatorial F region vertical drift model, J. Geophys., Res., 104(A4), 6829$6842,1999$.

Su, Y. Z., Oyama, K.-I., Bailey, G. J., Fukao, S., Takahashi, T., and Oya, H.: Longitudinal variations of the topside ionosphere at low latitudes: Satellite measurements and mathematical modelings, J. Geophys. Res., 101, 17 191-17 206, 1996.

Su, S.-Y., Lin, C. H., Ho, H. H., and Chao, C. K.: Distribution characteristics of topside ionospheric density irregularities: Equatorial versus midlatitude regions, J. Geophys. Res., 111, A06305, doi:10.1029/2005JA011330, 2006.

Vichare, G. and Richmond, A. D.: Simulation study of the longitudinal variation of evening vertical ionospheric drifts at the magnetic equator during equinox, J. Geophys. Res., 110, A05304, doi:10.1029/2004JA010720, 2005.

Walker, G. O.: Longitudinal structure of the F-region equatorial anomaly- A review, J. Atmos. Terr. Phys, 43, 763-775, 1981.

Whalen, J. A.: Dependence of the equatorial anomaly and of equatorial spread $\mathrm{F}$ on the maximum prereversal $\mathrm{E} \times \mathrm{B}$ drift velocity measured at solar maximum, J. Geophys. Res., 108 (A5), 1193, doi:10.1029/2002JA009755, 2003. 